\title{
Summer drought stress: differential effects on cane anatomy and non-structural carbohydrate content in overwintering Cabernet Sauvignon and Syrah vines
}

\author{
Rachele Falchi ${ }^{1,2^{*}}$, Elisa Petrussa ${ }^{1}$, Marco Zancani ${ }^{1}$, Valentino Casolo ${ }^{l}$, Paola Beraldo ${ }^{l}$, Andrea Nardini $^{3}$, Paolo \\ Sivilotti $^{1}$, Alberto Calderan ${ }^{l}$, Jose Carlos Herrera ${ }^{1,4}$, Enrico Peterlunger ${ }^{l}$, Enrico Braidot ${ }^{1}$ \\ ${ }^{1}$ University of Udine, Department of Agricultural, Food, Environmental and Animal Sciences, 33100 Udine, Italy \\ ${ }^{2}$ Bordeaux Science Agro, Institut des Sciences de la Vigne et du Vin, Ecophysiologie et Génomique Fonctionnelle de la Vigne, \\ UMR 1287, F- 33140, Villenave d'Ornon, France \\ ${ }^{3}$ University of Trieste, Department of Life Sciences, 34127 Trieste, Italy \\ ${ }^{4}$ University of Natural Resources and Life Sciences Vienna, Department of Crop Sciences, 3430 Tulln, Austria
}

\begin{abstract}
Grapevines store non-structural carbohydrates (NSC) during late summer to sustain plant development at the onset of the following spring's growth. Starch is the main stored carbohydrate, found in the wood-ray parenchyma of roots and canes. Although the relationship between hydraulic and plant photosynthetic performance is well-recognized, little research has been done on the longterm effects of drought in grapevines adopting different strategies to cope with water stress (i.e. isohydric and anisohydric). We performed our study by exposing two different grape cultivars (Syrah and Cabernet Sauvignon) to a short but severe drought stress, at two stages of the growing season (July and September). No marked differences in the physiological and hydraulic responses of the two varieties were found, probably due to our experimental conditions. However, anatomical and biochemical characterization of overwintering canes pointed out several interesting outcomes. We found a significant and parallel increase of starch and medullar ray number in both cultivars exposed to early water stress. We hypothesize that stressed vines limited their carbon allocation to growth, while shifting it to starch accumulation, with a most evident effect in the period of intense photosynthetic activity. We also speculate that a different aptitude to osmotic adjustment may underlay variation in starch increase and the specific involvement of bark NSC in the two cultivars.
\end{abstract}

\section{Introduction}

Deciduous trees and lianas such as grapevines accumulate non-structural carbohydrates (NSC) during favorable seasonal conditions to sustain plant respiration during winter and provide energy for canopy formation in early spring. Reserves are usually regarded as the total amount of starch and soluble carbohydrates stored in perennial vegetative organs [1]. Vines start redirection of carbohydrate assimilates toward storage organs after verraison and the typical seasonal dynamics of carbohydrate reserve concentrations in different organs vary greatly, due mainly to changes in starch amount which, at times, may exceed soluble sugars as much as 15 -fold [1-3]. The post-harvest period is crucial for the replenishment of carbohydrate reserves and the longevity of high yielding grapevines, in order to provide high levels of stored carbohydrates before dormancy and to sustain future crop productivity $[2,4]$.

Imposed water stress during fruit ripening is a worldwide common agronomical practice adopted to improve the final composition of grapes [5-7]. Even though grapevines, depending on the variety, are known as water stress tolerant plants, water deficit can also affect other physiological aspects of the plant, ranging from simple declines in stomatal conductance [8] to nonreversible effects upon re-watering [9]. As a result, the extent of the water restriction may cause severe leaf photosynthesis limitations, together with an increase in leaf senescence, thus resulting in important reduction in carbohydrate assimilation and partitioning [10].

There is little information about genetic influences on the tendency of grapevines to store NSC. However, cultivar associated differences do appear in response to environmental factors, such as water deficit, that affects stomatal conductance or photosynthesis [11]. In this perspective, it is likely that the perturbation of water status has dissimilar effects on NSC accumulation in grapevine genotypes..

Plants are frequently classified as isohydric or anisohydric in an attempt to describe their water relations strategy and the current use of this terminology normally refers to water management under long-term drought. However, this concept and its possible definitions have been recently revised [8, 12]. Multispecies comparison has shown that very few species 
conform strictly to definitions of isohydric or anisohydric [8]. Nonetheless, even if this precise distinction is not appropriate, it is now commonly accepted that grapevines are characterized by diverse hydraulic and photosynthetic behaviors, depending on the cultivar [6].

For this reason, we investigated the effects of a short yet severe drought stress imposed in two different periods of the growing season, on two cultivars of Vitis vinifera (Syrah and Cabernet Sauvignon), widely used for water stress studies by virtue of their different hydraulic behavior. The question we address here is whether this water deficit can affect key traits such as canes anatomy and NSC content during winter dormancy. Moreover, we outline dissimilar responses to drought stress, possibly dependent on the cultivar and on the date when water restriction occurs, arguing that it should impact long term vine productivity in a different way.

\section{Materials and methods}

\subsection{Plant material and experimental conditions}

The experiment was carried out at the University of Udine, experimental farm "A. Servadei", located in the Friuli Venezia Giulia region (north-eastern Italy; $46^{\circ} 02^{\prime}$ $\mathrm{N}, 13^{\circ} 13^{\prime} \mathrm{E} ; 88 \mathrm{~m}$ a.s.1.). Forty vines of Vitis vinifera $\mathrm{cv}$. Cabernet Sauvignon (CS) and 40 vines of cv. Syrah (SH), both grafted on SO4 rootstock, were planted in March 2016 in $7 \mathrm{~L}$ pots filled with a commercial potting media (Gebr. Brill Substrate Type 1, Georgsdorf, Germany) supplemented with $20 \%$ perlite. Bud break occurred on April 10th, and only one shoot per plant was left to develop vertically. For each cultivar, pots were arranged in 4 plots of 10 vines each in a fully randomized scheme encompassing 2 rows. To fully control irrigation and to avoid precipitation, pots were positioned under a sheltering structure.

Water was supplied by a drip irrigation system with one emitter per pot (PCJ $2 \mathrm{~L} \mathrm{~h}^{-1}$, Netafim, Israel). All vines were irrigated twice per day (at $2 \mathrm{pm}$ and at $11 \mathrm{pm}$ ) to saturation (well-watered; WW) until the imposition of water stress. Water stress (WS) was imposed by withholding irrigation completely for a period of 12 days; after that period irrigation was restored to saturation (i.e. as in WW) until leaf fall (November 1st, 2016). Water stress was imposed in two different periods on two different sets of plants: (i) early WS, on July 18th and (ii) late WS, on September 12th. For each treatment and cultivar, a group of randomly selected 10 vines was used; the remaining vines per cultivar were randomly divided in two groups of 10 vines each used as control during early and late WS, respectively.

Leaf area (LA) was assessed before the beginning of each trial to ensure similar plant size among the treatments. LA was calculated by measuring the leaf length of all the leaves in the shoots and using a regression between leaf length and leaf area previously determined using a leaf area meter (LI-3100C, LiCor, Inc., NE, USA).
Stem water potential $\left(\Psi_{\text {stem }}\right)$, stomatal conductance $\left(\mathrm{g}_{\mathrm{S}}\right)$ and net assimilation $\left(\mathrm{A}_{\mathrm{N}}\right)$ were measured at midday and during clear sunny days, every 2-3 days during the periods of water stress. For the determination of $\Psi_{\text {stem, }}$, young fully expanded leaves were bagged and covered with aluminum foil $1 \mathrm{~h}$ before the measurement, and then excised with a razor blade. Then the leaves were placed in a pressure chamber (Soil Moisture Co., Santa Barbara, USA) and $\Psi_{\text {stem }}$ assessed within few seconds. At each sampling point, one leaf of three different plants per treatment was used and no more than 2 leaves per vine were used during the whole period of WS. Stomatal conductance and net assimilation were measured with LI-6400 (LiCor, Inc., NE, USA), using a constant light intensity $\left(1000 \mu \mathrm{mol} \mathrm{m} \mathrm{m}^{-2} \mathrm{~s}^{-1}\right)$ and $\mathrm{CO}_{2}$ concentration $(400$ $\mu \mathrm{mol} \mathrm{mol}^{-1}$ ), on $2^{\text {nd }}-3^{\text {rd }}$ leaf and $5^{\text {th }}-7^{\text {th }}$ leaf (value averaged).

\subsection{Microscope analysis}

In January, after 5 or 3 months from the water stress treatments, four replicates of $10 \mathrm{~cm}$-segments for each combination (cultivar $\times$ treatment) were collected from the basal 5 th internode of randomly selected canes. $6-\mu \mathrm{m}$ microtome sections (stained with safranin/alcyan blue) were prepared and examined by light microscope (Fig. 1). Digital slides were acquired with an Aperio CS scanner (Leica, model AT2), at 5X magnification and anatomical parameters were analyzed by open-source ImageJ software. For bark parenchyma and phloem analysis, two orthogonal sections were selected from the total area.

For starch visualization and vital tissue observation, fresh $10-\mu \mathrm{m}$ microtome sections were stained with Lugol's Iodine or fluorescein diacetate solution and observed under stereomicroscope (Fig. 2) or under epifluorescence microscope.

\subsection{Cane non-structural carbohydrates (NSC) determination}

Glucose, sucrose, soluble starch degradation products (SSDP: maltose disaccharide fraction and maltodextrin oligosaccharides), and starch were extracted from the wood and the bark of each segment. NSC were measured by an enzymatic method [13].

\subsection{Statistical analysis}

The differences in $\Psi_{\text {stem }}, g_{S}$ and $A_{N}$ between WW and WS at the end of the period of water stress were evaluated by $t$-test (p indicated), separately for the stress periods of July and September.

One-way ANOVA was performed on NSC content and anatomical features data keeping separated the two grapevine cvv. When the differences were significant, SNK-test was applied to evaluate the differences between WW and WS $(p<0.05)$. The statistical analysis was performed with JMP 7.0 (SAS Institute Inc.), while point scatter graphs were prepared using SigmaPlot 13 (Systat Software GmbH, Erkrath, Germany). 


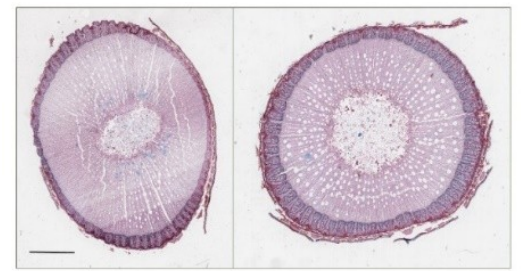

Fig. 1. Transverse 6- $\mu \mathrm{m}$ microtome sections of $V$. vinifera $\mathrm{L}$. stems stained with safranin/alcyan blue acquired under visible light. Drought stressed (late WS) CS (left panel) and SH (right panel) samples were examined under digital scanning microscope. Bar, $1 \mathrm{~mm}$.

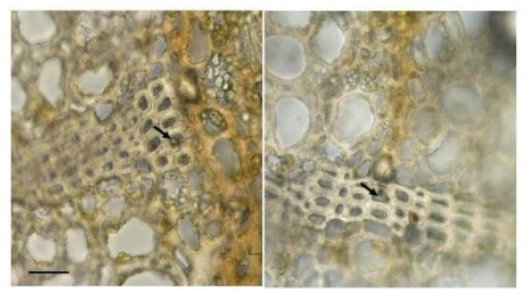

Fig. 2. Transverse $10-\mu \mathrm{m}$ microtome sections of $V$. vinifera $\mathrm{L}$. stems at the bark portion, stained with Lugol's iodine acquired under visible light at the stereomicroscope. Starch granules (arrows) are visible in the tangential bands of dead fibers in the phloem of CS (left panel) and SH (right panel) samples. Bar, $10 \mu \mathrm{m}$.

\section{Results}

\subsection{Vines water status}

Stomatal conductance $\left(\mathrm{g}_{\mathrm{S}}\right)$ can be considered as an indicator of water stress level. Medrano et al. [14] and Cifre et al. [15] identified three main levels of water deficit based on the measurement of $g_{S}$ : mild stress $\left(g_{S}>\right.$ $\left.0.15 \mathrm{~mol} \mathrm{H}_{2} \mathrm{O} \mathrm{m}^{-2} \mathrm{~s}^{-1}\right)$, moderate $\left(\mathrm{g}_{\mathrm{s}}\right.$ between 0.05 and $\left.0.15 \mathrm{~mol} \mathrm{H}_{2} \mathrm{O} \mathrm{m}^{-2} \mathrm{~s}^{-1}\right)$ and severe $\left(\mathrm{g}_{\mathrm{S}}<0.05 \mathrm{~mol} \mathrm{H}_{2} \mathrm{O} \mathrm{m}^{-2}\right.$ $\left.\mathrm{s}^{-1}\right)$. In our work, values $\leq 0.05 \mathrm{~mol} \mathrm{H}_{2} \mathrm{O} \mathrm{m}^{-2} \mathrm{~s}^{-1}$ were reached in both varieties over the final stages of the early WS test for both varieties (Table 1). On the other hand, in case of late WS, stomatal conductance reached values characteristic of moderate stress. The corresponding trends of stem water potential $\left(\Psi_{\text {stem }}\right)$ indicated that the plants reached levels of severe water stress in all treatments, with a more significant effect in case of early stress. However, no specific differences in the hydraulic behavior of the two varieties were found.

Net carbon assimilation $\left(A_{N}\right)$ reached values close to zero in early WS, while it stayed above $11 \mu \mathrm{mol} \mathrm{m}-2 \mathrm{~s}-1$ in WW. Late stress imposition determined a reduction in leaf photoassimilation (Table 1), resulting not significant in Syrah plants and significant at $\mathrm{P}<0.05$ in Cabernet Sauvignon.

Table 1 - Average values of stomatal conductance $\left(\mathrm{g}_{\mathrm{s}}, \mathrm{mol} \mathrm{H}_{2} \mathrm{O}\right.$ $\left.\mathrm{m}^{-2} \mathrm{~s}^{-1}\right)$, net assimilation $\left(\mathrm{A}_{\mathrm{N}}, \mu \mathrm{mol} \mathrm{CO}_{2} \mathrm{~m}^{-2} \mathrm{~s}^{-1}\right)$, and stem water potential $\left(\Psi_{\mathrm{S}}, \mathrm{MPa}\right)$, measured during the two water stress periods (early and late) in CS and SH grapevines. WW, wellwatered; WS, water stress.

\begin{tabular}{|l|l|c|c|c|}
\hline cultivar & treatment & $\mathbf{g}_{\mathbf{s}}$ & $\mathbf{A}_{\mathbf{N}}$ & $\mathbf{\Psi}_{\mathbf{S}}$ \\
\hline \multirow{5}{*}{ Cabernet S } & WW & 0.256 & 11.7 & -0.53 \\
\cline { 2 - 5 } & early WS & 0.016 & 0.10 & -1.23 \\
\cline { 2 - 5 } & sign & $* *$ & $* * *$ & $* *$ \\
\cline { 2 - 5 } & WW & 0.333 & 9.86 & -0.37 \\
\cline { 2 - 5 } & late WS & 0.097 & 5.86 & -1.24 \\
\cline { 2 - 5 } & sign & $* * *$ & $*$ & $*$ \\
\hline \multirow{5}{*}{ Syrah } & WW & 0.287 & 11.2 & -0.55 \\
\cline { 2 - 5 } & early WS & 0.012 & 0.42 & -1.33 \\
\cline { 2 - 5 } & sign & $* * *$ & $* * *$ & $* *$ \\
\cline { 2 - 5 } & WW & 0.239 & 5.48 & -0.6 \\
\cline { 2 - 5 } & late WS & 0.051 & 3.07 & -1.43 \\
\cline { 2 - 5 } & sign & $* * *$ & $n . s$. & $*$ \\
\hline
\end{tabular}

\subsection{Anatomical traits and NSC content}

Samples from CS and $\mathrm{SH}$ canes were harvested during winter dormancy. In the two cultivars, drought significantly influenced the density of parenchyma rays per wood area, but differently for each of the two cultivars (Tables 2 and 3). In CS, regardless of the date of stress exposure, drought increased the number of rays, whereas in SH only late WS significantly affected their number by reducing it with respect to control. Moreover, $\mathrm{CS}$ seemed to be more prone than $\mathrm{SH}$ to change cane growth and its differentiation into dead tissues, once subjected to water deprivation. In accordance, early and late WS increased the percentage of dead bark. Since it is known that parenchymatic rays in both wood and bark cane represent a fundamental source of starch and soluble carbohydrates for the vine, we verified by Lugol's Iodine staining of starch granules in bark and wood portions. In the bark tissue, parenchymatic cells appeared fluorescent green (alive), whereas phloem tangential fibers were identified as dead (result not shown). Nonetheless, parenchyma was not the only source of starch accumulation, as even dead tangential bands of bark fibers were filled with starch granules in their lumen (Fig. 2).

Soluble NSC and starch were analyzed separately in the portions of bark (phloem and parenchyma associated with bands of phloem fibers) and wood (xylem elements, radial and axial parenchyma), respectively, allowing to specific discrimination among some of the most predominant soluble carbohydrate pools, in addition to starch concentration. This detailed analysis clearly evidenced that drought stress in CS variety affected only wood starch content, by a substantial increase, similar to the pattern observed in ray number per wood area. 
Table 2 - NSC content and anatomical features of CS canes exposed to early and late water stress (WS). Colors are used to emphasize differences between values: highest values are red and lowest are green; ns, not significant; ${ }^{*}, \mathrm{p}<0.05 ;{ }^{* *}, \mathrm{p}<$ $0.01 ; * * *, \mathrm{p}<0.001$.

\begin{tabular}{|c|c|c|c|c|}
\hline & \multicolumn{3}{|c|}{ treatments } & \multirow[b]{2}{*}{$\begin{array}{c}\text { sign. } \\
F\end{array}$} \\
\hline & WW & $\begin{array}{l}\text { early } \\
\text { WS }\end{array}$ & late WS & \\
\hline \multicolumn{5}{|l|}{ ANATOMY } \\
\hline$\%$ bark & 25.0 & 20.6 & 21.0 & $n s$ \\
\hline$\%$ wood & 64.1 & 65.3 & 68.8 & $n s$ \\
\hline $\mathrm{n}^{\circ}$ rays $/ \mathrm{mm}^{2}$ & $1.9 \mathrm{~b}$ & $3.5 \mathrm{a}$ & $3.0 \mathrm{a}$ & $*$ \\
\hline$\%$ dead bark & $0.12 \mathrm{~b}$ & $0.13 \mathrm{ab}$ & $0.15 \mathrm{a}$ & $*$ \\
\hline \multicolumn{5}{|c|}{ WOOD $(\mu \mathrm{mol} / \mathrm{g} \mathrm{DW})$} \\
\hline glucose & 86.0 & 119.2 & 99.9 & $n s$ \\
\hline sucrose & 119.4 & 89.6 & 91.7 & $n s$ \\
\hline SSDP & 60.9 & 37.8 & 37.7 & $n s$ \\
\hline starch & $301.2 \mathrm{~b}$ & $404.9 \mathrm{a}$ & $350.6 \mathrm{ab}$ & * \\
\hline \multicolumn{5}{|c|}{ BARK $(\mu \mathrm{mol} / \mathrm{g} \mathrm{DW})$} \\
\hline glucose & 141.8 & 106.5 & 106.7 & $n s$ \\
\hline sucrose & 147.0 & 135.6 & 118.2 & $n s$ \\
\hline SSDP & 30.4 & 28.0 & 20.0 & $n s$ \\
\hline starch & 140.1 & 184.2 & 114.6 & $n s$ \\
\hline
\end{tabular}

Table 3 - NSC content and anatomical features of SH canes exposed to early and late water stress (WS). Data are analyzed and represented as described above (Table 2).

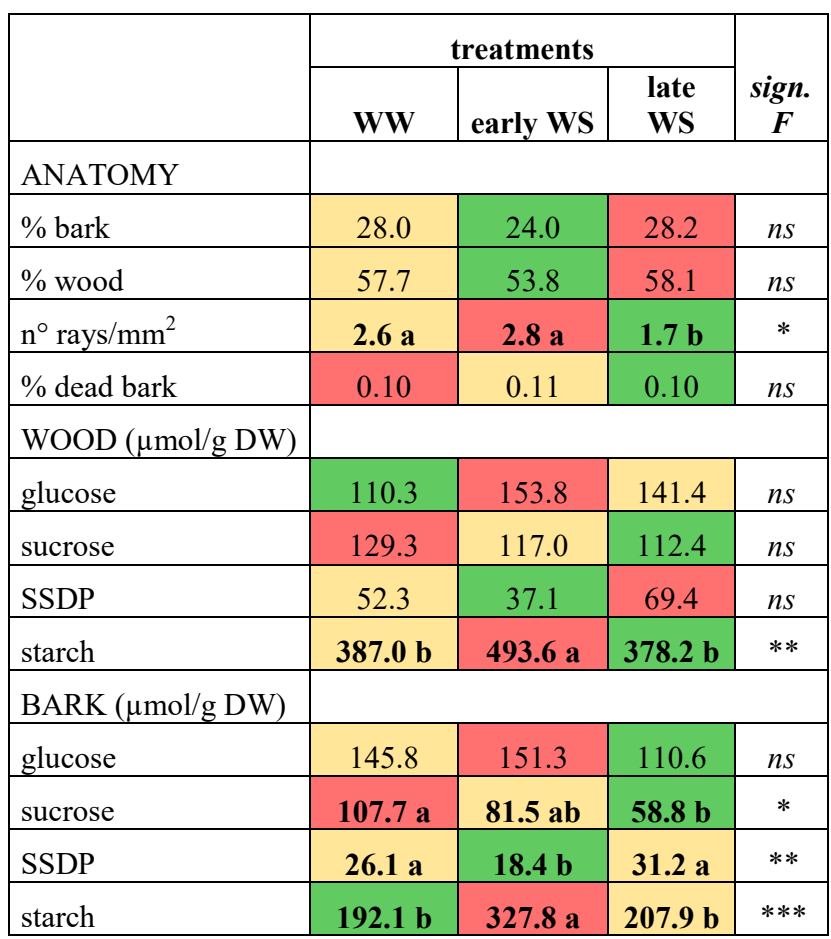

In $\mathrm{SH}$, starch significantly increased in early WS samples, in both wood and bark. This trend appeared consistent with the number of ray/wood area. More noteworthy, some of the investigated soluble NSC was also strongly affected in the bark of this cultivar: soluble starch degradation product (SSDP) concentration increased in drought stressed samples showing a consistent and inverse relationship with starch content. Moreover, in SH, both WS treatments lowered sucrose pool of the bark, as expected, whether or not foliar and bark clorenchyma photosynthesis were impaired.

\section{Discussion}

In woody plants, such as the grapevine, the storage of carbohydrate reserves during the summer and autumn in permanent organs is very important and affects vine longevity and quality potential at harvest of the following season $[16,17]$. In grapevines, starch is the main stored carbohydrate, located in the wood-ray parenchyma of roots and canes [3].

A link between hydraulic and photosynthetic performance in CS and SH has been previously reported and CS was found to behave in a near isohydric manner, whereas SH displayed a near anisohydric attitude [18].

In this work, we examined the influence of short but intense water stress imposed either in July or in September, on CS and SH grapevines, with special regard to the effects on overwintering canes.

Contradictory reports appear in the literature showing that the same variety could differently behave depending on experimental conditions [10]; i.e. SH in several studies shows a near-isohydric response [19]. Similarly, in our experimental conditions the average values of $g_{s}$, $\mathrm{A}_{\mathrm{N}}$, and $\Psi_{\text {stem }}$, measured during the two water stress periods, in both genotypes, did not display substantial differences. In early WS, significantly lower $g_{s}$ and $A_{N}$ were measured in both cultivars. On the other hand, in late WS, relatively high $g_{s}$ and a slight decrease in $A_{N}$ were observed in both cultivars. We support the idea that discrepancies between varieties should be ascribed to specific experimental conditions, that may have smoothed possible dissimilarities, rather than to the true genetic differences in stomatal control $[19,20]$.

It is well-recognized that leaf water status interacts with stomatal conductance and transpiration and that the decline in intercellular $\mathrm{CO}_{2}$, following stomatal closure and the lower light use efficiency under drought, may induce, in the long-term, a down-regulation of the photosynthetic machinery $[14,21]$. We found a significant and parallel increase of starch and medullar rays number, both in $\mathrm{CS}$ and in $\mathrm{SH}$ canes that underwent early WS. SH showed a considerable accumulation of starch (both in wood and in bark tissues), a consistent decrease in its degradation products and a gain in ray number. To a lesser extent, CS exhibited a similar pattern, with higher level of starch in early WS (in wood) and an analogous trend for ray number and dead bark proportion. These observations are apparently in contradiction with the observation of a decline in carbohydrate production in stressed plants, even invoking the circadian rhythm in stomatal function [21].

We hypothesize that this event can be attributed to two main reasons: i) our experiment used young grapevine plants with no fruits grown in small pots; ii) water stress imposed was relatively short. It is likely that 
the fast responses of the photosynthetic and carbon metabolism machinery to drought stress, in our conditions, have led the vines to respond not so much by reducing carbohydrates production, but rather by achieving a different assimilate partitioning, including storage of reserves in the canes or roots. In agreement with recent observations in laurel plants subjected to water deprivation [22], it could be hypothesized that stressed vines limited their carbon allocation to growth, while shifting it to starch accumulation in bark and wood parenchyma of the canes.

However, the effects in $\mathrm{SH}$ vines appeared more evident, indicating a possible greater aptitude of this cultivar to store starch reserves for plant survival under stress conditions, or, conversely, it may indicate that starch is possibly used as a source of osmoticum, required to cope with severe drought stress in CS variety. Further studies are needed to fully validate this hypothesis. The effects on starch and medullar rays amount is also reasonably different in the two periods, being the consequences of early stress more effective. It is possible that the earlier stress was concomitant with a period of intense photosynthetic activity, when assimilates are translocated to storage organs; whereas in the late period, vines did not have the same responsiveness to abiotic stress.

In conclusion, our findings show that our experimental conditions did not allow a clear differentiation of the "typical" isohydric and anysohidric behaviors for CS and SH cultivars. However, we provide a first hint about the anatomical and biochemical differences in overwintering canes of these two varieties. Early water stress applied on non-productive young plants leads to increased amount of starch reserves and this effect is particularly evident in SH, where we detected an involvement of bark tissue in the NSC partition. On the other hand, CS exhibited reserve storage mainly in wood tissue, whose area is, percentage-wise, more highly represented than in SH. This feature allows maintenance of an adequate water transport without lowering potential to dangerous values. Indeed, water stress, and the late one in particular, induced in CS an anatomical response, as confirmed by the increase of mechanical elements in the bark. Therefore, we can speculate that, despite the similarity in stomatal conductance dynamics, cultivar-specific stressresponse mechanisms, carrying structural and physiological consequences, have occurred. In particular, stress conditions induced metabolic adaptations in the case of $\mathrm{SH}$, while anatomical modifications characterized CS stress response. Similar indications may have important and practical implications, if confirmed in open field, allowing to take into account the long-term impact of drought conditions in different grape varieties.

\section{References}

1. B.P. Holzapfel, J.P. Smith, S.K. Field, W.J. Hardie. Horticultural reviews. (Edited by Janick J, 2010)
2. A. Pellegrino, P. Clingeleffer, N. Cooley, R. Walker. Front Plant Sci. 5:283 (2014)

3. C. Zapata, E. Deleens, S. Chaillou, C. Magne. J Plant Physiol. 161(9):1031-1040 (2004)

4. J.P. Smith, B.P. Holzapfel. Am J Enol Viticul. 60(4):461 (2009)

5. J.C. Herrera, U. Hochberg, A. Degu, P. Sabbatini, N. Lazarovitch, S.D. Castellarin, A. Fait, G. Alberti, E. Peterlunger. J Agric Food Chem. 65(29):5868-5878 (2017)

6. J.M. Mirás-Avalos, D.S. Intrigliolo. Front Plant Sci. 8:851 (2017)

7. P. Sivilotti, C. Bonetto, M. Paladin, E. Peterlunger. Am J Enol Viticul. 56(1),9 (2005)

8. U. Hochberg, F.E. Rockwell, N.M. Holbrook, H. Cochard. Trends Plant Sci. 23(2),112-120 (2018)

9. J. Flexas, M. Badger, W.S. Chow, H. Medrano, C.B. Osmond. Plant Physiol. 121(2), 675-684 (1999)

10. M.M. Chaves, O. Zarrouk, R. Francisco, J.M. Costa, T. Santos, A.P. Regalado, M.L. Rodrigues, C.M. Lopes. Ann Bot-London. 105(5), 661-676 (2010)

11. G.R. Cramer, S.C. Van Sluyter, D.W. Hopper, D. Pascovici, T. Keighley, P.A. Haynes. BMC Plant Biol. 13, 49 (2013)

12. J. Martinez-Vilalta, N. Garcia-Forner. Plant Cell Environ. 40(6), 962-976 (2017)

13. A.G. Quentin, E.A. Pinkard, M.G. Ryan, D.T. Tissue, L.S. Baggett, H.D. Adams, P. Maillard, J. Marchand, S.M. Landhausser, A. Lacointe et al. Tree Physiol. 35(11), 1146-1165 (2015)

14. H. Medrano, J.M. Escalona, J. Bota, J. Gulìas, J. Flexas. Ann Bot-London. 89(7), 895-905 (2002)

15. J. Cifre, J. Bota, J.M. Escalona, H. Medrano, J. Flexas. Agr Ecosyst Environ. 106(2), 159-170 (2005)

16. H.A. Mooney, B.L. Gartner. The Biology of Vines (Cambridge University Press, 1992).

17. V. Zufferey, F. Murisier, P. Vivin, S. Belcher, F. Lorenzini, J. Spring, O. Viret. Vitis. 51(3), 103110 (2012)

18. U. Hochberg, A. Degu, A. Fait, S. Rachmilevitch. Physiol Plant. 147(4):443-452 (2013)

19. H.R. Schultz. Plant Cell Environ. 26(8):13931405 (2003)

20. F Tardieu and T. Simonneau. J Exp Bot. 49:419432 (1998)

21. M.M. Chaves, J.S. Pereira, J. Maroco, M.L. Rodrigues, C.P.P. Ricardo, M.L. Osório, I. 
Carvalho, T. Faria, C. Pinheiro. Ann Bot-London. 89(7):907-916 (2002)

22. P. Trifilò, V. Casolo, F. Raimondo, E. Petrussa, F. Boscutti, M.A. Lo Gullo, A. Nardini. Plant Physiol Biochem. 120:232-241 (2017) 